\title{
The ulnar nerve in the cubital tunnel: a foetal study
}

\author{
D.N. Bailey ${ }^{1}$, S. Ishwarkumar²®, B.Z. De Gama1', P. Pillay ${ }^{1}$ \\ ${ }^{1}$ Department of Clinical Anatomy, School of Laboratory Medicine and Medical Sciences, College of Health Sciences, \\ University of KwaZulu-Natal, Westville Campus, Durban, South Africa \\ ${ }^{2}$ Department of Human Anatomy and Physiology, Faculty of Health Sciences, University of Johannesburg, \\ Doornfontein Campus, South Africa
}

[Received: 27 August 2020; Accepted: 1 November 2020; Early publication date: 30 December 2020]

Background: The ulnar nerve (UN), a terminal branch of the medial cord of the brachial plexus, is located posteromedial to brachial artery coursing along medially in the arm from the anterior to the posterior compartment through the arcade of Struthers. It passes posterior to medial epicondyle of humerus and enters the cubital tunnel. Then, it exits through the distal part of the cubital fossa to enter the medial side of the forearm between the two heads of the flexor carpi ulnaris muscle underneath Osborne's ligament to enter the anterior compartment of the forearm. Entrapment of the UN at the cubital tunnel results in a pain and a tingling sensation on the medial side of the forearm and fourth and fifth digits. Materials and methods: This foetal study documented the course of the UN within the cubital tunnel and its anatomical relations utilising bilateral microscopic dissection of 25 foetuses (gestational age: 19-36 weeks).

Results: The UN followed the standard anatomical course in 96\% (48/50) of the specimens, however it was found to lie deep to the muscles of the cubital tunnel in $6 \%(3 / 50)$. The radial artery joined the UN distal to the cubital tunnel in $8 \%$ (4/50), while the superior ulnar collateral artery was posteriorly related to the UN in 32\% (16/50) of specimens. The Osborne's ligament (crossed between the two heads of the flexor carpi ulnaris muscle, posterior to the medial epicondyle of the humerus) was present in all specimens $100 \%$ (50/50). It had a mean length of $6.32 \pm 0.97 \mathrm{~mm}$ and $6.30 \pm 1.10 \mathrm{~mm}$ on the left and right sides, respectively. The current study observed that the flexor pronator aponeurosis was present in $2 \%(1 / 50)$ of specimens.

Conclusions: Knowledge of the normal and variable anatomical course of the UN in the cubital tunnel in this study may assist in the diagnosis and treatment of compressive neuropathy of the UN in the cubital tunnel. (Folia Morphol 2022; 81, 1: 31-36)

Key words: ulnar nerve, cubital fossa, foetal study and anatomical course

Address for correspondence: Dr. P. Pillay, Department of Clinical Anatomy, School of Laboratory Medicine and Medical Sciences, College of Health Sciences, University of KwaZulu-Natal, Private Bag X54001, Durban, 4000, South Africa, tel: + 2731260 7789, fax: + 27312607890 , e-mail: soobramoneypa@ukzn.ac.za

This article is available in open access under Creative Common Attribution-Non-Commercial-No Derivatives 4.0 International (CC BY-NC-ND 4.0) license, allowing to download articles and share them with others as long as they credit the authors and the publisher, but without permission to change them in any way or use them commercially. 


\section{INTRODUCTION}

The ulnar nerve (UN) is the larger terminal branch of the medial cord of the brachial plexus formed by the ventral rami of $\mathrm{C} 8$ and $\mathrm{T} 1$, with occasional branches from $C 7[4,23]$. In its course, it runs on the medial side of the brachial artery in the middle-third of the arm, pierces the medial intermuscular septum with the superior ulnar collateral artery (SUCA), runs in the arcade of Struthers between the septum and the medial head of the triceps $[5,18]$. The arcade of Struthers is described as a musculotendinous band, located at variable distances superior to the medial epicondyle of the humerus between the medial intermuscular septa and the medial head of the triceps brachii muscle $[5,8,16]$. The UN then passes posterior to the medial epicondyle of humerus, to enter the forearm medial to the olecranon of the ulna [15, 18]. At this juncture, a tendinous ligamentous arch is stated to span between the humeral and ulnar heads of flexor carpi ulnaris (FCU) muscle which is referred to as the Osborne's ligament $[10,19]$. The cubital tunnel is a fibromuscular canal beneath the Osborne's ligament [20]. The Osborne's ligament forms the roof of the canal laterally, and the floor is formed by the medial collateral ligament, the joint capsule of elbow and olecranon process [19]. This tunnel can be divided into three parts: viz. (i) the entrance posterior to the medial epicondyle; (ii) the fascial aponeurosis joining two heads of the FCU, and (iii) at the muscular bellies [22].

The UN slopes postero-medially together with the ulnar vessels in the forearm deep to anterior margin of FCU and flexor digitorum profundus (FDP), giving motor branches to both muscles [21].

Typically, compression of the UN occurs at the cubital tunnel; however, the nerve is also vulnerable at other sites around the elbow [15, 20]. These sites are classified as either pre-cubital, cubital tunnel or post-cubital tunnel compression sites $[6,20]$. Since, the compression sites are variable, anatomical knowledge of the relations of the UN is important $[4,15,20]$.

Therefore, this study aimed at documenting the course of the UN with a focus on the anatomical relations within the cubital tunnel.

\section{MATERIALS AND METHODS}

A bilateral dissection of 25 foetal cadavers $(n=50)$, 11 females and 14 males between 19 and 36 gestational weeks, was performed to expose muscles of the forearm and reveal the UN in the cubital tunnel, in order to document its course and relations. The presence of the arcade of Struthers, anconeus epitrochlearis muscle, flexor-pronator aponeurosis (FPA), Osborne's ligament, the SUCA, radial artery and ulnar artery was also documented together with anatomical variations (if present). A morphometric analysis of the Osborne's ligament was performed by measuring the distance between the medial epicondyle and the lateral border of the olecranon process using a digital sliding calliper in order to determine the size of the cubital tunnel. The foetal cadavers were sourced from the Department of Clinical Anatomy at the University of KwaZulu-Natal (Westville Campus). Ethical clearance was obtained (BE397/17). Foetuses whose forearms were deformed by traumas, malformations, scars or any other macroscopic evidence of pathology were excluded from this study. The data was captured and analysed using the Statistical Package for Social Sciences (SPSS version 23.0) software. A p-value of less than 0.05 was deemed statistically significant.

\section{Reliability and validity}

Morphometric analysis of the Osborne's ligaments was performed by an inter-observer on 5 random cadavers using the sliding digital calliper. The intra-class correlation coefficient test was then employed to assess the inter-observer reliability. A 0.989 significance for the mean Osborne's ligament length between both observers was found which denotes excellent agreement.

\section{RESULTS}

\section{The course and relations of the ulnar nerve}

The UN passed through the cubital tunnel in $96 \%$ $(48 / 50)$ of the specimens, while it was absent in $4 \%$ $(2 / 50)$ (Fig. 1). In its course through the cubital tunnel, the UN was located deep to the FCU and supero-lateral to the FDP in $6 \%$ (3/50) (Fig. 2). The SUCA accompanied the UN into the cubital tunnel in $32 \%$ $(16 / 50)$ in at least one side of the present study prior to its anastomoses with the ulnar recurrent arteries (Figs. 3, 4; Table 1). A statistically significant correlation between the course of the UN and SUCA was documented in this study with a p-value of 0.042 .

The ulnar artery accompanied the UN as it passes through the cubital fossa in $34 \%$ (17/50) (Figs. 5, 6). In $2 \%(1 / 50)$ of the specimens, the UN was covered medially by a common flexor pronator aponeurosis (Fig. 7). The radial artery followed the standard anatomical course in $92 \%(46 / 50)$ of the specimens; 


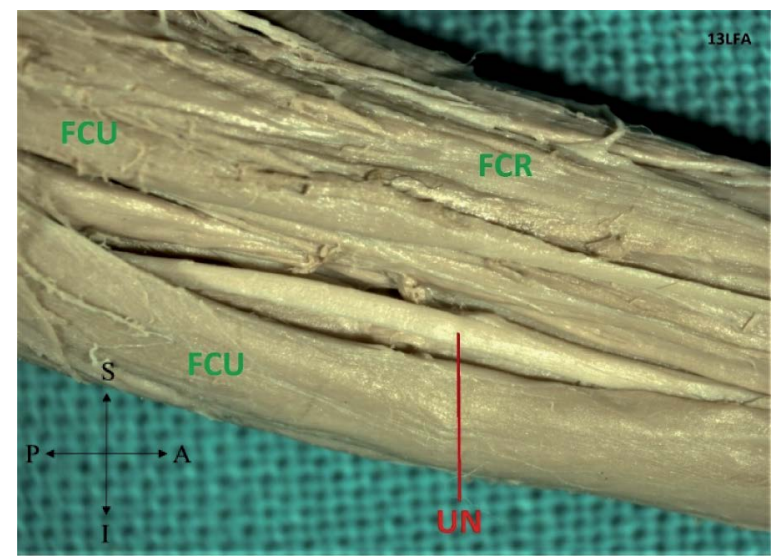

Figure 1. The standard description of ulnar nerve (UN) in the cubital tunnel; FCR — flexor carpi radialis; FCU — flexor carpi ulnaris.

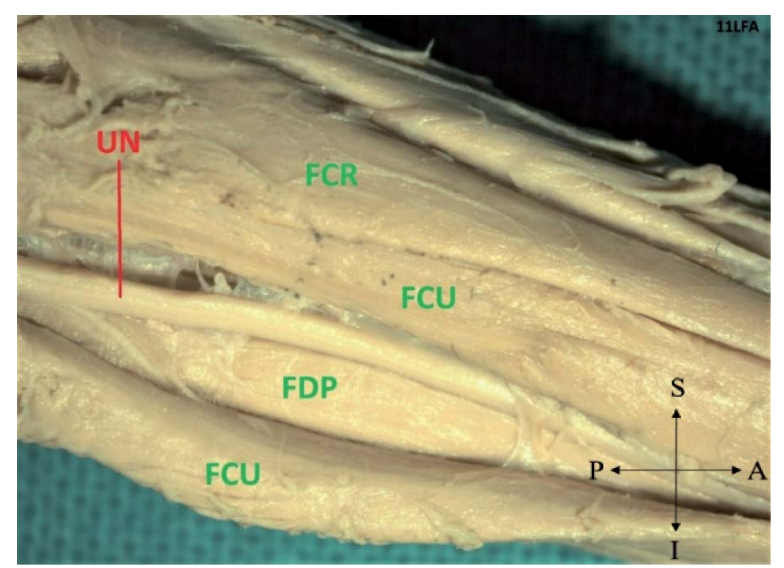

Figure 2. The ulnar nerve (UN) lies deep to the cubital tunnel muscles; FCR — flexor carpi radialis; FCU — flexor carpi ulnaris; FDP — flexor digitorum profundus.

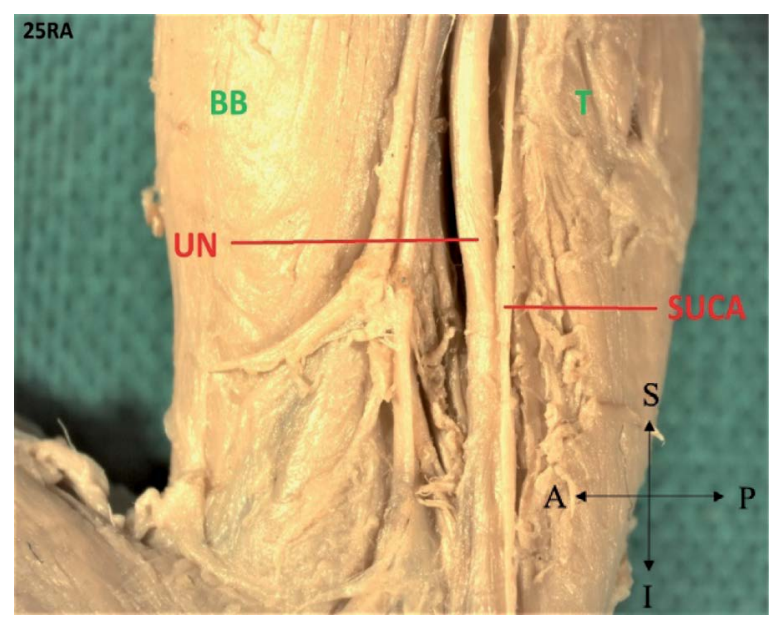

Figure 3. The ulnar nerve (UN) in the arm accompanied by the superior ulnar collateral artery (SUCA); BB — biceps brachii; $\mathrm{T}$ - triceps muscle.

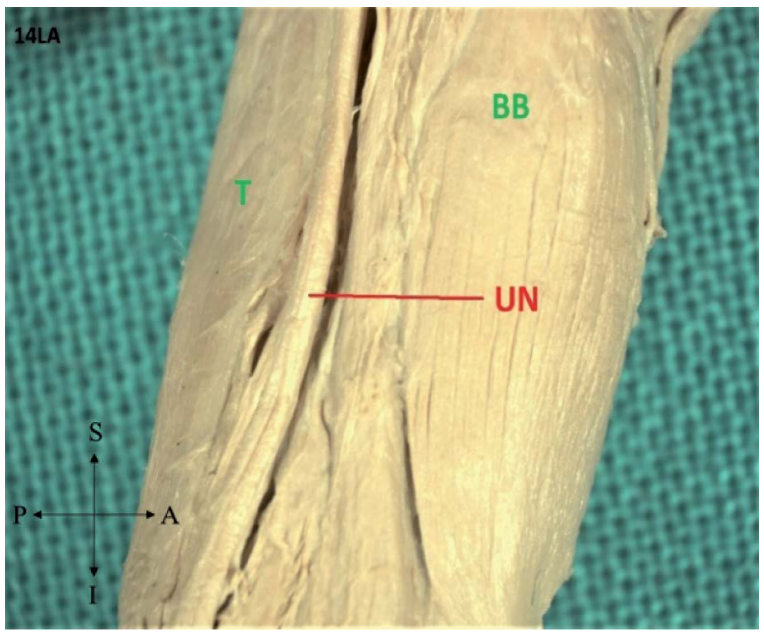

Figure 4. The ulnar nerve (UN) in arm without the superior ulnar collateral artery (SUCA); BB - biceps brachii; $\mathrm{T}$ - triceps muscle.

Table 1. Presence/absence of the superior ulnar collateral artery in relation to laterality $(n=50)$

\begin{tabular}{lcc}
\hline & Incidence & Percentage \\
\hline Present on left side only & 5 & $10 \%$ \\
Present on right side only & 3 & $6 \%$ \\
Bilaterally present & 8 & $16 \%$ \\
Bilaterally absent & 26 & $52 \%$ \\
Absent on left side only & 5 & $10 \%$ \\
Absent on right side only & 3 & $6 \%$ \\
\hline
\end{tabular}

however, it accompanied the UN distal to the cubital tunnel in $8 \%(4 / 50)$ (Fig. 8).

\section{Arcade of Struthers}

All specimens sampled in this study showed that the arcade of Struthers was absent. This may be due to the developmental stages of foetuses used.

\section{Osborne's ligament}

The Osborne's ligament was found in $100 \%$ of specimens (50/50) (Fig. 9), but varied from a thin aponeurotic structure to a thickened fascial band. The anconeus epitrochlearis muscle, an analogue to the Osborne's ligament was found in $2 \%(1 / 50)$ of the specimens (Fig. 10). The Osborne's ligament had a mean length of $6.32 \pm 0.97$ and $6.30 \pm 1.10 \mathrm{~mm}$ on the left and right sides, respectively (Table 2). This study found no statistically significant relationship between the length of Osborne's ligament and laterality (right: $p=0.55$ and left $p=0.65$ ). 


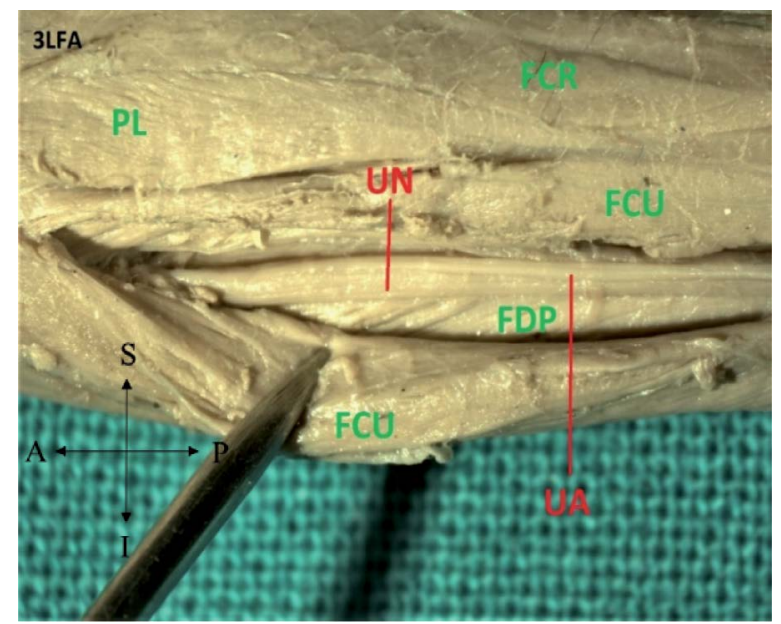

Figure 5. The ulnar nerve (UN) in the cubital tunnel and forearm accompanied by the ulnar artery (UA); FCR — flexor carpi radials; FCU — flexor carpi ulnaris; FDP — flexor digitorum profundus; $\mathrm{PL}$ - palmaris longus.

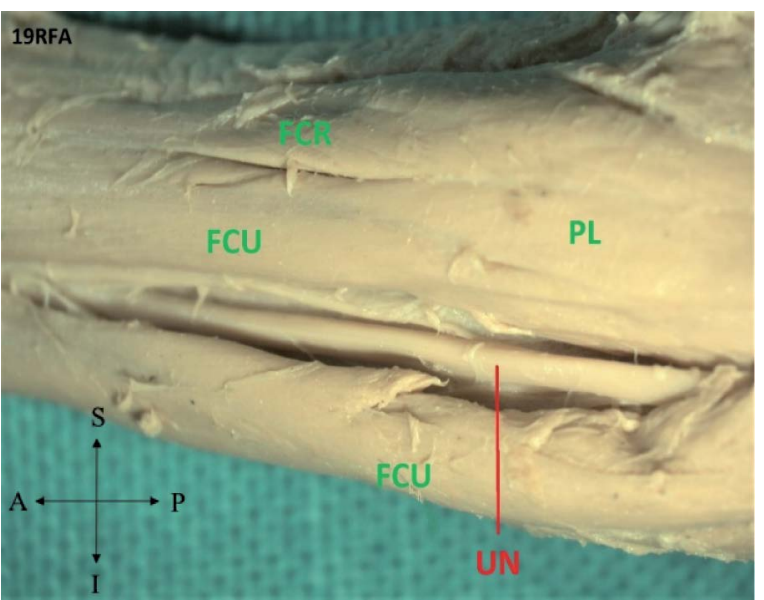

Figure 6. The ulnar nerve (UN) in the cubital tunnel without the ulnar artery; FCR - flexor carpi radialis; $\mathrm{PL}$ — palmaris longus; FCU - flexor carpi ulnaris.

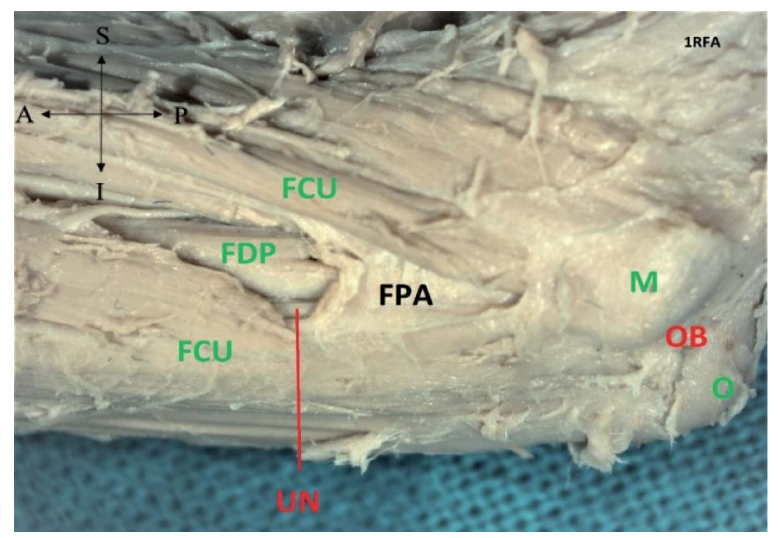

Figure 7. The flexor pronator aponeurosis (FPA) underneath heads of flexor carpi ulnaris (FCU); FDP — flexor digitorum profundus; $\mathrm{OB}$ - Osborne's band; UN — ulnar nerve; $\mathrm{M}$ - medial epicondyle; 0 - olecranon process.

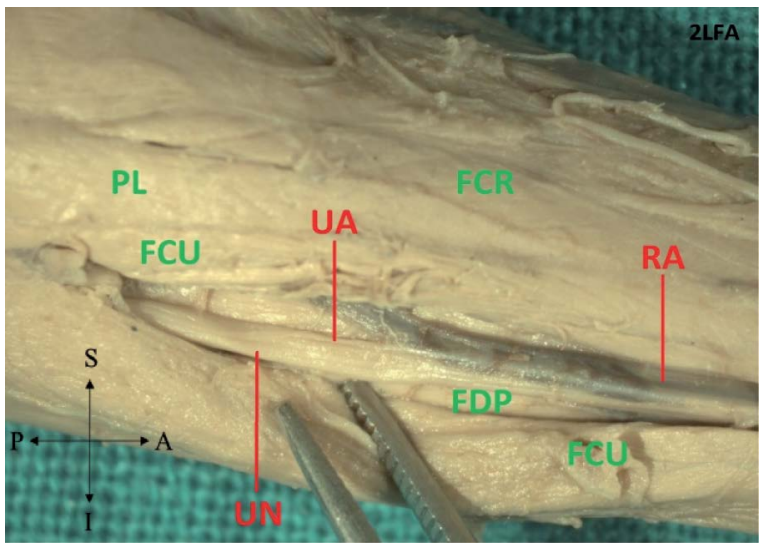

Figure 8. The ulnar nerve (UN) accompanied by the radial artery (RA); FCR — flexor carpi radialis; FCU — flexor carpi ulnaris; FDP — flexor digitorum profundus; $\mathrm{PL}$ — palmaris longus; UA — ulnar artery.

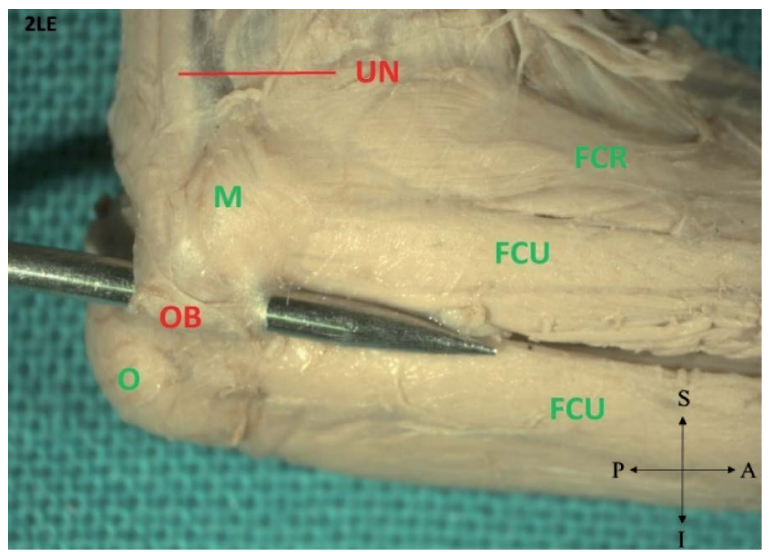

Figure 9. The Osborne's ligament between the two heads of flexor carpi ulnaris (FCU); UN — ulnar nerve; $\mathrm{M}$ - medial epicondyle; $\mathrm{OB}$ - Osborne's band; 0 - olecranon process; FCR - flexor carpi radialis.

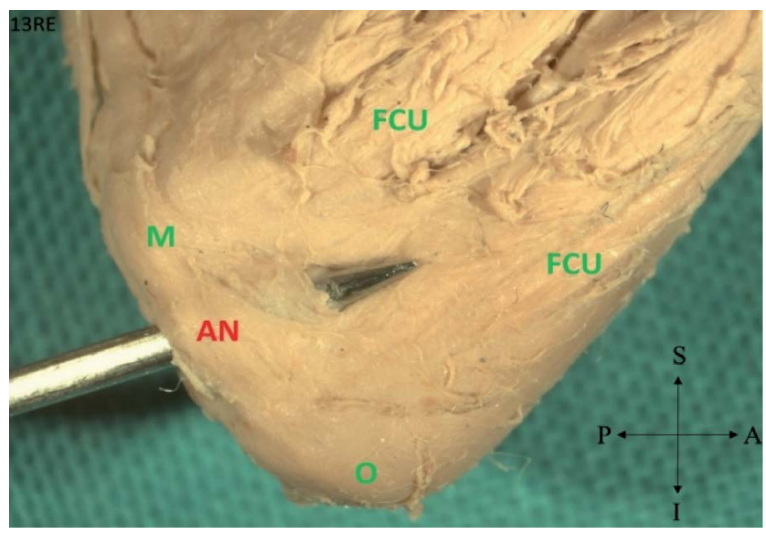

Figure 10. The anconeus epitrochlearis (AN) muscle between the two heads of the flexor carpi ulnaris (FCU); $\mathrm{M}$ - medial epicondyle; 0 - olecranon process. 
Table 2. Mean length and standard deviations of Osborne's ligament

\begin{tabular}{lcccc}
\hline & Minimum length [mm] & Maximum length [mm] & Mean length [mm] & Standard deviation \\
\hline Age [weeks] & 19.49 & 36.93 & 26.55 & 3.73 \\
Right Osborne's ligament & 4.64 & 8.82 & 6.30 & 1.09 \\
Left Osborne's ligament & 4.48 & 8.69 & 6.32 & 0.97 \\
\hline
\end{tabular}

Table 3. Descriptions of the flexor-pronator aponeurosis (FPA) in the cadaver studies

\begin{tabular}{lcccc}
\hline Author & Year & Sample size & FPA (present/absent) & Length [cm] \\
\hline Inserra and Spinner [13] & 1986 & 10 & Absent & $1.5-2.0$ \\
Amadio and Beckenbaugh [1] & 1986 & 20 & $100 \%$ & 5 \\
Green and Rayan [11] & 1999 & 19 & $100 \%$ & 2.9 \\
Gonzalez et al. [9] & 2001 & 38 & $43.5 \%$ & 4.2 \\
Degeorges and Masquelet [7] & 2002 & 24 & $45.8 \%$ & 6 \\
Siemionow et al. [20] & 2007 & 28 & $100 \%$ & 5.6 \\
Present study & 2017 & 50 & $2 \%$ & Not measured \\
\hline
\end{tabular}

\section{DISCUSSION}

The course and relations of the ulnar nerve

This study found that in $96 \%$ (48/50) of the specimens, the standard course of the UN was documented, viz. the nerve crosses the medial collateral ligament of the elbow and enters the flexor compartment of the forearm between the two heads of the FCU, then travelled distally between the FCU and FDP muscles $[12,15,17]$.

However, the course of the UN can vary. Assmus et al. [2] documented the UN in the cubital tunnel whereby the nerve had a superficial course, anterior to the medial epicondyle but did not penetrate the fascia between the FCU muscles. In this study, the radial artery accompanied the $U N$, distal to the cubital tunnel, from the middle third of the forearm was documented as a unique finding.

An elliptically shaped fibrous tunnel formed by the flexor pronator aponeurosis was observed (2\%); however, previous literature indicated the incidence of the FPA to range between $43.5 \%$ and $100 \%$ (Table 3 ) $[1,7,9,11,13,20]$. Siemionow et al. [20] documented that the elliptically shaped tunnel may be a cause of UN compression.

\section{Arcade of Struthers}

The arcade of Struthers was observed in previous literature $[15,20]$, however it was not present in the specimens used in this study. This could be due to the sample size or the use of foetuses instead of adult cadavers. Furthermore, Bartels et al. [3] and Caetano et al. [5] stated that the occurrence of the arcade of Struthers is rare and observed in $0.7 \%$ to $2.5 \%$ of the population. Furthermore, Mizia et al. [16] found that the arcade of Struthers is a valid anatomical structure that is present in most individuals; however, its presence is highly variable.

\section{Osborne's ligament}

An Osborne's ligament was documented in 100\% of specimens; however, the ligament varied from a very thin aponeurotic structure to a thickened muscle. An anconeus epitrochlearis muscle found in one of the specimens, has been described as the cause of UN neuritis [14]. The mean length of the Osborne's ligament in this study was $6.32 \pm 0.97 \mathrm{~mm}$ on the left side and $6.30 \pm 1.10 \mathrm{~mm}$ on the right side (Table 2). The length of the Osborne's ligament differed with previous reports such as Gonzalez et al. [9] who found its average length as $4.6 \mathrm{~mm}$. Variations in the length of the Osborne's ligament to a previous study can be attributed to the fact that previous studies were conducted on adult cadavers, while the current study was conducted on foetuses.

The SUCA accompanied the UN into the cubital tunnel in $32 \%$ and a significant correlation was observed between presence of the superior ulnar collateral artery and the course of UN. 


\section{Limitations of the study}

The present study only included foetal specimens, as there is a shortage of adult cadavers. A further study is required to document the histology of the Osborne's ligament as this was not done in this study.

\section{CONCLUSIONS}

The understanding of the anatomy of the UN is important for the diagnosis and treatment of conservative and surgical lesions of the UN in the cubital region. In this study, the potential sites of UN compression may be at the cubital tunnel; beneath the FCU; FPA (elliptically shaped tunnel) and the Osborne's ligament. Knowledge of the anatomy of the UN in the cubital tunnel may be essential to mitigate the risk of injury during the now increasingly performed endoscopically assisted decompression surgery [2].

\section{Acknowledgements}

“Dr. P. Pillay is a University of KwaZulu-Natal (UKZN) Developing Research Innovation, Localisation and Leadership in South Africa (DRILL) fellow. DRILL, is a NIH D43 grant (D43TW010131) awarded to UKZN in 2015 to support a research training and induction programme for early career academics. The content is solely the responsibility of the authors and does not necessarily represent the official views of DRILL and the National Institutes of Health."

The authors of this study sincerely wish to thank and acknowledge the human foetal cadaveric donors and their families for the donation of their remains to science. This selfless donation enabled us to conduct this anatomical study and contribute to the existing knowledge of the UN in the cubital tunnel, which may assist in foetal surgical procedures. We truly appreciate theses donations to anatomical science.

\section{Conflict of interest: None declared}

\section{REFERENCES}

1. Amadio P, Beckenbaugh R. Entrapment of the ulnar nerve by the deep flexorpronator aponeurosis. J Hand Surg. 1986; 11(1): 83-87, doi: 10.1016/s0363-5023(86)80110-1.

2. Assmus H, Antoniadis G, Bischoff C. Carpal and cubital tunnel and other, rarer nerve compression syndromes. Dtsch Arztebl Int. 2015; 112(1-2): 14-25; quiz 26, doi: 10.3238/ arztebl.2015.0014, indexed in Pubmed: 25613452.

3. Bartels RH, Grotenhuis JA, Kauer JMG. The arcade of Struthers: an anatomical study. Acta Neurochir (Wien). 2003; 145(4): 295-300; discussion 300, doi: 10.1007/s00701003-0006-5, indexed in Pubmed: 12748890.

4. Becker R, Manna B. Anatomy, upper limb, elbow, nerves, ulnar. StatPearls Publishing, Treasure Island (FL) 2018.
5. Caetano EB, Sabongi Neto JJ, Vieira LA, et al. The arcade of Struthers: an anatomical study and clinical implications. Rev Bras Ortop. 2017; 52(3): 331-336, doi: 10.1016/j. rboe.2016.07.006, indexed in Pubmed: 28702393.

6. Cutts S. Cubital tunnel syndrome. Postgrad Med J. 2007; 83(975): 28-31, doi: 10.1136/pgmj.2006.047456, indexed in Pubmed: 17267675.

7. Degeorges R, Masquelet AC. The cubital tunnel: anatomical study of its distal part. Surg Radiol Anat. 2002; 24(3-4): 169-176, doi: 10.1007/s00276-002-0032-7, indexed in Pubmed: 12375068.

8. Depukat $\mathrm{P}$, Mizia $\mathrm{E}$, Zwinczewska $\mathrm{H}$, et al. Topography of ulnar nerve and its variations with special respect to carpal region. Folia Med Cracov. 2014; 54(4): 45-58, indexed in Pubmed: 25891242.

9. Gonzalez MH, Lotfi P, Bendre A, et al. The ulnar nerve at the elbow and its local branching: an anatomic study. J Hand Surg Br. 2001; 26(2): 142-144, doi: 10.1054/ jhsb.2000.0532, indexed in Pubmed: 11281666.

10. Granger A, Sardi JP, Iwanaga J, et al. Osborne's ligament: a review of its history, anatomy, and surgical importance. Cureus. 2017; 9(3): e1080, doi: 10.7759/cureus.1080, indexed in Pubmed: 28405530.

11. Green JR, Rayan GM. The cubital tunnel: anatomic, histologic, and biomechanical study. J Shoulder Elbow Surg. 1999; 8(5): 466-470, doi: 10.1016/s1058-2746(99)90078-2, indexed in Pubmed: 10543601.

12. Heithoff SJ. Cubital tunnel syndrome: ulnar nerve subluxation. J Hand Surg Am. 2010; 35(9): 1556; author reply 1556-7, doi: 10.1016/j.jhsa.2010.06.027, indexed in Pubmed: 20807635.

13. Inserra $S$, Spinner M. An anatomic factor significant in transposition of the ulnar nerve. J Hand Surg. 1986; 11(1): 80-82, doi: 10.1016/s0363-5023(86)80109-5.

14. Joshi SD, Joshi SS. Study of cubital tunnel. J Anat Soc India. 2002; 51(2): 173-175.

15. Macchi V, Tiengo C, Porzionato A, et al. The cubital tunnel: a radiologic and histotopographic study. J Anat. 2014; 225(2): 262-269, doi: 10.1111/joa.12206, indexed in Pubmed: 24917209.

16. Mizia E, Zarzecki MP, Pekala JR, et al. An anatomical investigation of rare upper limb neuropathies due to the Struthers' ligament or arcade: a meta-analysis. Folia Morphol. 2021; 80(2): 255-266, doi: 10.5603/FM.a2020.0050, indexed in Pubmed: 32394418.

17. Moore KL. Clinically Oriented Anatomy 6th Ed. Lippincott, Williams and Wilkins, Baltimore, MD 2010: 770.

18. Moore KL, Dalley AF, Agur AMR. Clinically orientated anatomy. Lippincott, Williams and Wilkins 2014: 514-516.

19. Sawardeker P, Kindt KE, Baratz NE. Nerve Compression: Ulnar Nerve of the Elbow. 2015.

20. Siemionow M, Agaoglu G, Hoffmann R. Anatomic characteristics of a fascia and its bands overlying the ulnar nerve in the proximal forearm: a cadaver study. J Hand Surg Eur Vol. 2007; 32(3): 302-307, doi: 10.1016/J. JHSB.2006.12.015, indexed in Pubmed: 17321018.

21. Standring S. Gray's Anatomy E-Book: The Anatomical Basis of Clinical Practice. Elsevier Health Sciences 2015.

22. Xarchas KC, Psillakis I, Koukou O, et al. Ulnar nerve dislocation at the elbow: review of the literature and report of three cases. Open Orthop J. 2007; 1: 1-3, doi: 10.2174/1874325000701010001, indexed in Pubmed: 19461901.

23. Yamada K, Nagaoka M, Nagao S, et al. Anatomical study of osborne ligament elongation in relation to elbow flexion. J Nihon University Med Ass. 2013; 72(3): 154-158, doi: 10.4264/numa.72.154. 